\title{
Botulinum toxin abdominal wall injection and post-omphalocele ventral hernia repair: database and proposal of a protocol
}

\author{
Lisieux Eyer de Jesus ${ }^{1,2^{*}}$ (D) Thais Cardoso Leve ${ }^{2}$, Celine Fulgencio ${ }^{2}$ and Samuel Dekermacher ${ }^{2}$
}

\begin{abstract}
Background: Post-omphalocele ventral hernias (POVH) are common after giant omphaloceles. Abdominal wall botulinum toxin injections (BTI) are useful to treat complex incisional hernias $(\mathrm{CIH})$ in adults, which may also apply to POVH. We review BTI data in the treatment of $\mathrm{CIH}$ and POVH and propose an algorithm applicable to POVH.

Results: Sixteen papers which described the treatment of $\mathrm{CIH}$ on the treatment of $\mathrm{POVH}$ in adults $(n=15)$ and children $(n=1)$ were reviewed. BTI elongates the lateral abdominal wall and reduces the hernia defect, with a lower incidence of compartment syndrome and respiratory complications. Doses and injection volumes vary. Effects start after 3 days, peak after 10-15 days, stabilize for 2-3 months, and decline after 4-6 months, disappearing after 6-9 months. Patients should be operated on 3-4 weeks after injection. Post-operative complications are uncommon. BTI may be associated with pre-operative pneumoperitoneum (PPP). Children presenting POVH differ from adults presenting $\mathrm{ClH}$. Associated congenital cardiac malformations, genetically determined syndromes, pulmonary hypoplasia, abdominal wall hypoplasia, and thoracic dysmorphism, are common; children need sedation for any procedures; non-absorbable reinforcing meshes are not indicated; and POVH limits are frequently near to the costal margin.
\end{abstract}

Conclusion: BTI to induce preoperative muscular relaxation in preparation of $\mathrm{ClH}$ repair in adults is effective and safe. Experience with the method in children with POVH is limited, but the proposal is logical and probably safe. POVH differs from $\mathrm{ClH}$ in some aspects, especially abdominal wall hypoplasia, proximity to the rib cage, and diaphragmatic biomechanics.

Keywords: Giant omphalocele, Ventral hernia, Incisional hernia, Botulinum toxin

\section{Background}

Patients presenting big ventral hernias characteristically show lateral retraction of the abdominal muscles, relative hypertonia of those muscles [1], and an abnormal posture (hyperlordosis). Their treatment shows high recurrence (12-56\%), morbidity (mainly respiratory problems and wound complications), and costs [2].

Inter or intra-muscular botulinum toxin injections (BTI) in the lateral abdominal wall to expand the

\footnotetext{
*Correspondence: lisieux@uol.com.br; lisieuxeyerdejesus@gmail.com ${ }^{1}$ Antônio Pedro University Hospital/School of Medicine, Federal Fluminense University, 52 Presidente Domiciano St apt 801, Boa Viagem, Niterói, Rio de Janeiro ZIP code 24210270, Brazil

${ }^{2}$ Servidores do Estado Federal Hospital/Health Ministry, Rio de Janeiro, Brazil
}

abdominal cavity come from experimental research aiming for future treatment of post-omphalocele ventral hernias $(\mathrm{POVH})$, in 2006. Carknak et al. proved that from 3 days after BTI in multiple intramuscular abdominal sites, abdominal compliance augmented, so that the cavity expanded to bear approximately $20 \%$ more volume than in the animals of the sham group, without augmenting abdominal pressure. Electromyography (EMG) proved that the injected musculature was inactive or hypoactive in the experimental group [3].

Other authors inferred that this could be useful in the treatment of complex incisional hernias $(\mathrm{CIH})$, hypothesizing that planned relaxation of the abdominal musculature around the hernia defect could facilitate closure

\section{Springer Open}

(c) The Author(s). 2020 Open Access This article is licensed under a Creative Commons Attribution 4.0 International License, which permits use, sharing, adaptation, distribution and reproduction in any medium or format, as long as you give appropriate credit to the original author(s) and the source, provide a link to the Creative Commons licence, and indicate if changes were made. The images or other third party material in this article are included in the article's Creative Commons licence, unless indicated otherwise in a credit line to the material. If material is not included in the article's Creative Commons licence and your intended use is not permitted by statutory regulation or exceeds the permitted use, you will need to obtain permission directly from the copyright holder. To view a copy of this licence, visit http://creativecommons.org/licenses/by/4.0/. 
without intra-abdominal hypertension, avoiding prosthetic mesh bridging repairs (related to higher incidences of recurrence and complications) [4]. BTI has been proved to counteract the tension of the abdominal wall and to reduce hernia size (frequently turning bridged repairs into direct repairs or direct repairs facilitated by myofascial compartment mobilization - MCM). This logic may also apply to POVH secondary to conservative treatment of omphaloceles or after complications of the planned closure of neonatal omphaloceles.

Data concerning BT injections to facilitate closure of $\mathrm{CIH}$ are restricted to a few surgical groups working in referral centers. In what concerns the treatment of $\mathrm{POVH}$, only two case reports are available, one of those in Danish [5, 6].

We aim to review the clinical experience with BTI in the treatment of $\mathrm{CIH}$, to substantiate the proposal of a logical protocol to be used in children with POVH.

\section{Methods}

Descriptive non-systematic literature review using the databases PUBMED and Google Scholar. Two searches were made using the MESH terms (1) ("INCISIONAL HERNIA" or "VENTRAL HERNIA") AND (BOTOX or "BOTULINUM TOXIN") and (2) (OMPHALOCELE or EXOMPHALOS) AND (BOTOX or "BOTULINUM TOXIN"). A review of the references of the retrieved papers was also done to retrieve any other relevant papers. All papers concerning the theme were reviewed, in English, Portuguese, or Spanish.

\section{Results}

\section{$\mathrm{BTI}$ previous to the repair of $\mathrm{ClH}$}

A total of 17 papers were reviewed. One case report described the treatment of a POVH in a 7-year-old child [5]. All other papers referred to the treatment of $\mathrm{CIH}$ in adults (11 retrospective [1, 4, 7-15] and 2 prospective $[16,17]$ and 2 reviews $[2,18]$. Five papers come from the same department in Australia and may have included the same patients $[1,4,8,9,17]$, as well as 2 from the same hospital in Spain [10, 11], 2 from Mayo Clinic (USA) [14, 15], and 2 from Ibarra-Hurtado's group from Mexico [13, 17], making it difficult to do a systematic analysis or even reliable counting the total of treated cases. We opted to insert in the summary tables the first [9] and the last [4] published retrospective papers from Elstner group and the first paper of Ibarra-Hurtado group (as the second paper lacks some technical details present in the first one) [13]. Bueno-Lledo papers [10, 11] were not included in the tables because they explored the association of BTI and preoperative programmed pneumoperitoneum (PPP).

Abdominal wall $\mathrm{BT}$, also described in the literature as chemical component separation, leads to muscular elongation and reduction of the thickness of the lateral abdominal wall [19], less postoperative pain $[15,20]$, lower incidence of compartment syndrome, and ventilatory/respiratory complications. The injection of BT leads to $30-50 \%$ reduction on the abdominal defect and of the area of the hernia defect after $3-4$ weeks $[1,4,7,17]$ and elongates about $2.4-4.1 \mathrm{~cm} /$ side of the wall (transversely), in adults $[1,13]$. Some propose that BTI may also be used preemptively to avoid postoperative ventral hernias in high-risk selected cases [2].

The technique consists of BTI in the muscular lateral wall of the abdomen (transverse abdominal muscle TAM, internal oblique muscle - IOM and external oblique muscle - EOM), mostly guided by ultrasound (US), into the muscles or in the intermuscular space. A paper proposes studying the muscular activity with EMG, to better define the functional muscles to be injected, avoiding injections into non-functional/scarred areas of the abdominal wall [17]. The injection sites must be lateral to the rectus abdominis muscle compartment. Although the precise sites may be determined by ultrasound, the authors suggest injecting $3-5$ points in each side, distributed between the flank/medium axillary line (MAA), anterior high abdominal quadrants inferior to the ninth rib (anterior axillary line - AAL), and anterior/superior to the iliac crest, on the inferior abdominal quadrants. Considering that the TAM function is mainly truncal stabilization, while the oblique muscles function to promote and coordinate movement, Elstner et al. recently proposed to restrict the injections to the EOM and IOM, sparing TAM. A prospective study comparing the "classical" 3-layer injection to this proposal showed similar results [16] (Table 1).

Doses and injection volumes vary from 100 [7] to 500 IU [10] (Table 2). Dysport $\odot$ doses should be calculated as 3 times the doses of Botox@.

The effects of the injection start after 3 days, peak after 10-15 days, stabilize for $2-3$ months, and decline after 4-6 months, disappearing after 6-9 months. The results are maximal 3 weeks after the injection [17]. Most authors agree that the patients should ideally be operated on about 4 weeks after injection, to take profit of the plain effect of the injection and also of the persistent muscular relaxation predicted to persist at least for the next 3 months, to minimize tension on the repair during early cicatrization, as well as to diminish post-operative pain (BT interferes with neurotransmitters and avoids post-operative reactive muscle spasm) [9].

The methods used to repair the hernia vary between authors, from (1) direct closing after approximation of the two sides of the abdominal wall, with or without reinforcing the repair with prosthetic meshes and (2) anterior or posterior MCM (Table 3). No monitoring of abdominal pressure was used. The 
Table 1 BTI methodology to treat ClH: guidance, number, and local of injections

\begin{tabular}{|c|c|c|c|c|}
\hline Author & Method & $\begin{array}{l}\text { Number of } \\
\text { injections/side }\end{array}$ & Local of injections & Distribution \\
\hline Ibarra-Hurtado et al. 2009 [17] & EMG guided & 5 & EOM & AAL (2), MAL (3) \\
\hline Ibarra-Hurtado et al. 2014 [13] & US guided & 5 & Inter muscular: EOM-IOM & AAL (2), MAL (3) \\
\hline Elstner et al. 2016 [19] & US guided & 3 & EOM - IOM - TAM & $\begin{array}{l}\text { AAL (3), next to the 9th rib (1), next to the } \\
\text { anterior iliac crest (1) }\end{array}$ \\
\hline Chavez-Tostado et al. 2014 [7] & $\begin{array}{l}\text { Without real time image } \\
\text { guiding }\end{array}$ & 5 & IOM & $\begin{array}{l}\text { AAL (3), next to the 9th rib (1), next to the } \\
\text { anterior iliac crest (1) }\end{array}$ \\
\hline Rodriguez-Acevedo et al. 2018 [4] & US guided & 5 & EOM - IOM - TAM & $\begin{array}{l}\text { AAL (3), next to the 9th rib (1), next to the } \\
\text { anterior iliac crest (1) }\end{array}$ \\
\hline Nielsen et al. 2019 [12] & US guided & 5 & EOM - IOM - TAM & $\begin{array}{l}\text { AAL (3), next to the 9th rib (1), next to the } \\
\text { anterior iliac crest (1) }\end{array}$ \\
\hline Zielinski et al. 2013 [14] & US guided & 3 & EOM - IOM - TAM & AAL (2), MAL (3) \\
\hline
\end{tabular}

results are better in central hernias, as compared to lateralized hernias.

Post-operative complications and side effects have been rarely reported, mostly "week cough," a bloating/ distended abdomen sensation and back pain [4]. Both complaints could be relieved with an abdominal binder [1]. Nielsen et al., however, differ from other authors and describe respiratory complications affecting $7 / 37$ of the patients, $1 / 37$ abdominal compartment syndrome, and $2 / 37$ cardiorespiratory arrest (without specifying the cause), in a cohort of patients with many comorbidities [12]. The complications seem to be related to abdominal closure, not to the usage of BTI. Abdominal compartment syndrome has been reported only by two groups, to the moment $[11,12]$. Post-operative results, in what concerns hernia resolution, are superior to than historical controls using similar surgical techniques without BTI. Respiratory complications, however, were more frequent in Nielsen's group than in historical series $(6 \%$ in published series without BTI versus $18,9 \%$ in Nielsen's cohort) [12]. The reasons for this are not easily explained, but a higher proportion of direct closure (versus bridged repairs) or the selection of severe cases in BTI group may be related.

Some papers associate BTI to other methods to prepare $\mathrm{CIH}$ patients for surgery, mainly PPP. Bueno-Lledo reviews the method [10], suggesting that while BTI allows muscular distension, favoring an augmentation of THE AREA of the abdominal wall, PPP facilitates volumetric distension of the abdominal cavity, allowing an augmentation of the VOLUME of the abdominal cavity, so that the two methods act as complementary. PPP may be more important in cases where the ratio hernia volume/abdominal volume is $>20 \%$ (hernias with loss of domain), which may be defined after measurements by CT [21]. PPP may also help to stabilize diaphragmatic function, promote adhesiolysis of loose adhesions, and promote peritoneal vasodilation, favoring cicatrization.

The authors differ in the methodologies to induce PPP. Most propose the installation of a left abdominal catheter (a catheter for central vascular access [10] or a pigtail catheter [4] can be used) and daily injection of air for 7-10 days pre-operatively (5-22) [10]. The volume injected depends on the tolerance of the patient, varying from 1000 to $1500 \mathrm{ml}$ and reaching 3 times the initial abdominal volume in adults [10]. Registered complications of PPP were very frequent $(20-50 \%)[4,8,11]$, varying from pain and vagal reactions from phrenic irritation [10] to pneumothorax, pneumomediastinum, and pneumopericardium, subcutaneous emphysema, metabolic acidosis, and the inadvertent puncture of an intestinal segment. All authors agree in using venous

Table 2 BTI to treat $\mathrm{ClH}$ : doses and dillutions

\begin{tabular}{|c|c|c|c|c|}
\hline Author & Total/case & Total/injection & Number of injections & Dillution \\
\hline Ibarra-Hurtado et al. 2009 [17] & $500 \mathrm{IU}$ disport & $50 \mathrm{IU} / 0.5 \mathrm{ml}$ & $5 /$ side & $100 \mathrm{lU} / \mathrm{ml}$ \\
\hline Ibarra-Hurtado et al. 2014 [13] & $500 \mathrm{IU}$ disport & $50 \mathrm{IU} / 0.5 \mathrm{ml}$ & $5 /$ side & $100 \mathrm{IU} / \mathrm{ml}$ \\
\hline Elstner et al. 2016 [9] & 300 IU botox & $16 \mathrm{IU} / 8 \mathrm{ml}$ & 3/side & $2 \mathrm{IU} / \mathrm{ml}$ \\
\hline Chavez-Tostado et al. 2014 [7] & 100 IU Botox & $10 \mathrm{IU} / 0.2 \mathrm{ml}$ & 5/side & $50 \mathrm{lU} / \mathrm{ml}$ \\
\hline Rodriguez-Acevedo et al. 2018 ${ }^{a}$ [4] & 200-300 IU botox ${ }^{b}$ & $16 \mathrm{IU} / 8 \mathrm{ml}$ & 3/side & $2 \mathrm{IU} / \mathrm{ml}$ \\
\hline Nielsen et al. 2019 [12] & 300 IU botox & $30 \mathrm{IU} / 6-15 \mathrm{ml}$ & 5/side & $2-5 \mathrm{IU} / \mathrm{ml}$ \\
\hline Zielinski et al. 2013 [14] & $300 \mathrm{IU}$ botox & $17 \mathrm{UI} / 8 \mathrm{ml}$ & $3 /$ side & $2 \mathrm{UI} / \mathrm{ml}$ \\
\hline
\end{tabular}

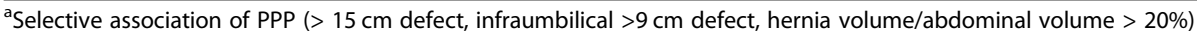

${ }^{\mathrm{b}}$ Similar results in 200 and $300 \mathrm{IU}$ groups 
Table 3 BTI to treat $\mathrm{ClH}$ : results

\begin{tabular}{|c|c|c|c|c|c|c|}
\hline Author & $n$ & Timing & Control & Defect & Surgery & Recurrences \\
\hline $\begin{array}{l}\text { Ibarra-Hurtado et al. } \\
2009 \text { [17] }\end{array}$ & 12 & & $\begin{array}{l}\mathrm{CT} \text { ( } 4 \text { and } 1 \text { preop } \\
\text { weeks) }\end{array}$ & Mean $13.9 \mathrm{~cm}$ & $\begin{array}{l}6 \text { direct closure+6 } \\
\text { anterior MCM }\end{array}$ & $\begin{array}{l}\text { None } \\
\text { (mean FU } 9 \text { mo, 4-18) }\end{array}$ \\
\hline Elstner et al. 2016 [9] & 32 & 14 weeks preop & $\begin{array}{l}\text { CT (preop, } 2 \text { mo Pop, } \\
6 \text { mo Pop) }\end{array}$ & $5 \times 9 \mathrm{~cm}$ to $24-27 \mathrm{~cm}$ & $\begin{array}{l}26 \text { direct closure } \\
\text { W/mesh reinforcement } \\
+6 \text { anterior MCM }\end{array}$ & $\begin{array}{l}\text { None } \\
\text { (mean FU } 19 \text { mo - 5-39) }\end{array}$ \\
\hline $\begin{array}{l}\text { Chavez-Tostado et al. } \\
2014 \text { [7] }\end{array}$ & 14 & $\begin{array}{l}\text { mean } 40.1 \text { preop } \\
\text { days }\end{array}$ & $\begin{array}{l}\mathrm{CT} \text { (4 and } 1 \text { preop } \\
\text { weeks) }\end{array}$ & Mean $14.6 \mathrm{~cm}\left(282 \mathrm{~cm}^{2}\right)$ & $\begin{array}{l}\text { 11/14 direct closure, } \\
3 / 14 \text { MCM, both } \\
\text { w/mesh reinforcement }\end{array}$ & $\begin{array}{l}\text { None } \\
\text { (mean FU } 34 \text { mo - 18-120) }\end{array}$ \\
\hline $\begin{array}{l}\text { Rodriguez-Acevedo } \\
\text { et al. } 2018 \text { [4] }\end{array}$ & 56 & 7-14 days preop & $\begin{array}{l}\text { CT (preop, } 10 \text { days post } \\
\text { TB injection, mo Pop, } 2 \\
\text { and } 6 \text { mo Pop) }\end{array}$ & $\begin{array}{l}\text { Mean } 11.6 \mathrm{~cm}(5 \times 9 \text { to } \\
28 \times 19 \mathrm{~cm})\end{array}$ & $\begin{array}{l}\text { 48/56 direct closure, } \\
8 / 56 \mathrm{MCM} \text {, both } \\
\text { w/mesh reinforcement }\end{array}$ & One (questionable) \\
\hline $\begin{array}{l}\text { Nielsen et al. } 2019 \\
\text { [12] }\end{array}$ & 37 & 3-4 weeks preop & CT & Mean $12 \times 20 \mathrm{~cm}$ & $\begin{array}{l}\text { 22/37 direct closure, } \\
\text { 15/37 MCM, both } \\
\text { w/mesh reinforcement }\end{array}$ & Not reported \\
\hline $\begin{array}{l}\text { Zielinski et al. } 2013 \\
\text { [14] }\end{array}$ & 18 & $\begin{array}{l}\text { Pre-closure } \\
\text { (open abdomen) }\end{array}$ & None & Not described & $\begin{array}{l}\text { 83\% primary closure, } \\
\text { 9/18 MCM }\end{array}$ & $\begin{array}{l}11 \% \text { recurrence, } 6 \% \\
\text { mortality }\end{array}$ \\
\hline
\end{tabular}

thrombosis prophylaxis for all patients being submitted to PPP [8].

\section{POVH in children}

The treatment of POVH may be extremely difficult and risky. Multiple technical propositions have been made. In some cases, a direct repair is impossible, even with anterior (eventually extended to the thoracic wall) or posterior MCM $[22,23]$. A bridged repair using absorbable prostheses (acellular collagen or acellular dermis) remains the option available for such cases, with high costs and higher incidences of recurrence.

Theoretically, the repair would be facilitated by (1) inducing volumetric growth of the abdominal cavity and adapting the diaphragm to higher intraabdominal pressures and (2) inducing the expansion of the abdominal wall.

Various methods are proposed and may be associated, such as abdominal binders/compression bandages [24, 25], intra-abdominal expanders [26], conditioning with periods bearing weights over the abdomen in the supine position and PPP. Binders, bandages, and weight conditioning are difficult to use in children and have not been proved effective. Intracavitary expanders require surgery to insert the expander, cannot be used in the presence of multiple adherences, need frequent injections to the port, and may complicate with infections and/or extrusion of the device. PPP demands a permanent intraabdominal catheter and is uncomfortable to the patient, limiting cooperation. All those methods are empirically used based on experts' opinions and lack evidence concerning timing, volumes to be instilled, effective weights, safe pressures, and results.

BTI has been proposed as an option in this situation just recently. Only two papers, both case reports, explore this option. One of them was published in a regional journal, in Danish, and was not included in this review [6]. The other available paper associates BTI and PPP. The patient was a 7-year-old child presenting a 9-cmdiameter $\mathrm{POVH}$ containing the left lobe of the liver. A total of $100 \mathrm{UI}$ of Botox $/ 50 \mathrm{ml}$ saline were used (50 UI/ side, $13 \mathrm{IU} / \mathrm{kg}$ ), directly injected in OEM/OIM/TAM using a 23-G needle connected to a perfusor (the same used for anesthetic TAP blocks). PPP was done with daily injections of air for 2 weeks through a 7-Fr permanent catheter (initiating 2 weeks after BTI). The total volume (about $2000 \mathrm{ml}$ ) was controlled by the level of the patient's discomfort [5]. An analysis of the paper suggests that the dose of BT used was proportionally higher than the doses used in adults (see Table 2) and higher than the maximum recommended pediatric doses (maximal dose of $8 \mathrm{IU} / \mathrm{kg}$ or $300 \mathrm{IU}$ ) recommended by the US Food and Drug Administration (FDA) [27]. Recommended doses to treat spasticity are $\leq 6 \mathrm{IU} / \mathrm{kg}$ [28] and doses of 3-5 IU/ kg have been used successfully to treat pediatric hyperactive bladder [29].

\section{Development of a protocol for POVH}

Although $\mathrm{CIH}$ and $\mathrm{POVH}$ are comparable in many points, important differences should be recognized as follows:

1. Adults' comorbidities (obesity, diabetes, status posttreatment for oncological diseases, and trauma) are mostly absent in children. However, other problems are associated with giant omphaloceles, especially congenital cardiac malformations, genetically determined syndromes, pulmonary hypoplasia, and thoracic dysmorphism [30].

2. While in adults with $\mathrm{CIH}$ there is retraction of normal abdominal muscular structures, in children 
with $\mathrm{POVH}$, there is also hypoplasia of the abdominal musculature.

3. Young children cannot cooperate and need sedation even for "minor" procedures.

4. The exposure to radiation from CT exams should be minimized in children, following ALARA principles.

5. Reinforcing meshes are not indicated in children, except for absorbable devices, so that pediatric repairs should preferably be based on approximation of autogenous tissues.

6. POVH superior limits may be very near the costal margin, which may limit the effectiveness of BTI. This aspect has to be tested prospectively and may prove to be a limitation of BTI in some POVH cases.

\section{Proposal of a protocol for POVH (Fig. 1)}

Evaluation of the response to BTI The method suggested in the literature for adults (repetitive CT volumetric and area measurements) is not appropriate for children. We propose to approximate volumes with direct body measurements (Fig. 2):

1. Transverse (a) and longitudinal (b) diameter of the hernia, plus height (c) of the hernia with the child supine.

2. Calculation of the hernia volume as the half of an ellipsoid $[(2 \times$ height $) \times$ transverse diameter $\times$ longitudinal diameter $\times 0.52] / 2$ or a sphere $[4 \times \pi \times$ $\left.(a / 2)^{3} / 3\right]$, depending on the hernia morphology.
3. Direct measurement of abdominal parameters, considering the abdomen as an ellipsoid to calculate abdominal volume: length $x$ transverse diameter $\times$ depth $\times 0.52$ (length: distance from the pubis to the xiphoid, transverse diameter: flank to flank distance, depth: anteroposterior diameter, excluding the hernia protrusion).

4. Calculation of the ratio between hernia volume/ abdominal volume. If this ratio is $\geq 20 \%$ patients are classified as severe cases.

Measurements are done pre-injection, 7 and 14 days post-BTI. If hernia volume/abdominal volume ratio persists higher than $20 \%$, the patients are selected for PPP, beginning 10 days preoperatively. US is also used to infer the hernia content (solid viscera versus intestine).

BT doses FDA proposes $8 \mathrm{IU}$ of botox (maximum 300 IU) as the safe limit for an isolated application in children [27]. We suggest $5 \mathrm{IU} / \mathrm{kg}$ (maximum $300 \mathrm{IU}$ ), diluted with saline into $5 \mathrm{IU}$ of botox $/ \mathrm{ml}$. In a $12-\mathrm{kg}$ child, for example, one would inject $60 \mathrm{IU}$ of botox, diluted to $12 \mathrm{ml}$, and $2 \mathrm{ml} /$ injection point, using 6 injection points).

Method of injection The injections should be guided by ultrasound under sedation and address the lateral abdominal wall musculature, 3 points/side (AAL under the ninth rib and superiorly to the anterior iliac spine and MAL between the ribs and iliac crest), 3-4 weeks before the date predicted for surgery, distributing equitably the volume into the three lateral muscles (EOM, IOM, TAM) at each injection point.

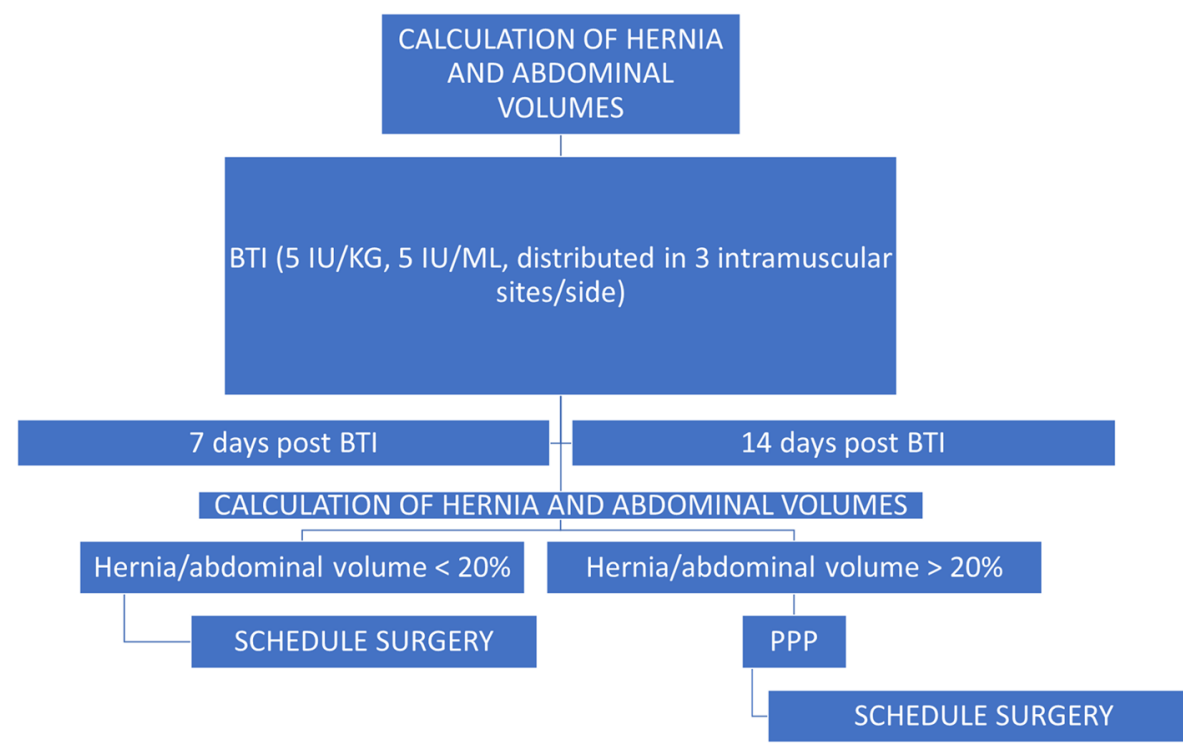

Fig. 1 Proposed algorithm for the treatment of POVH 


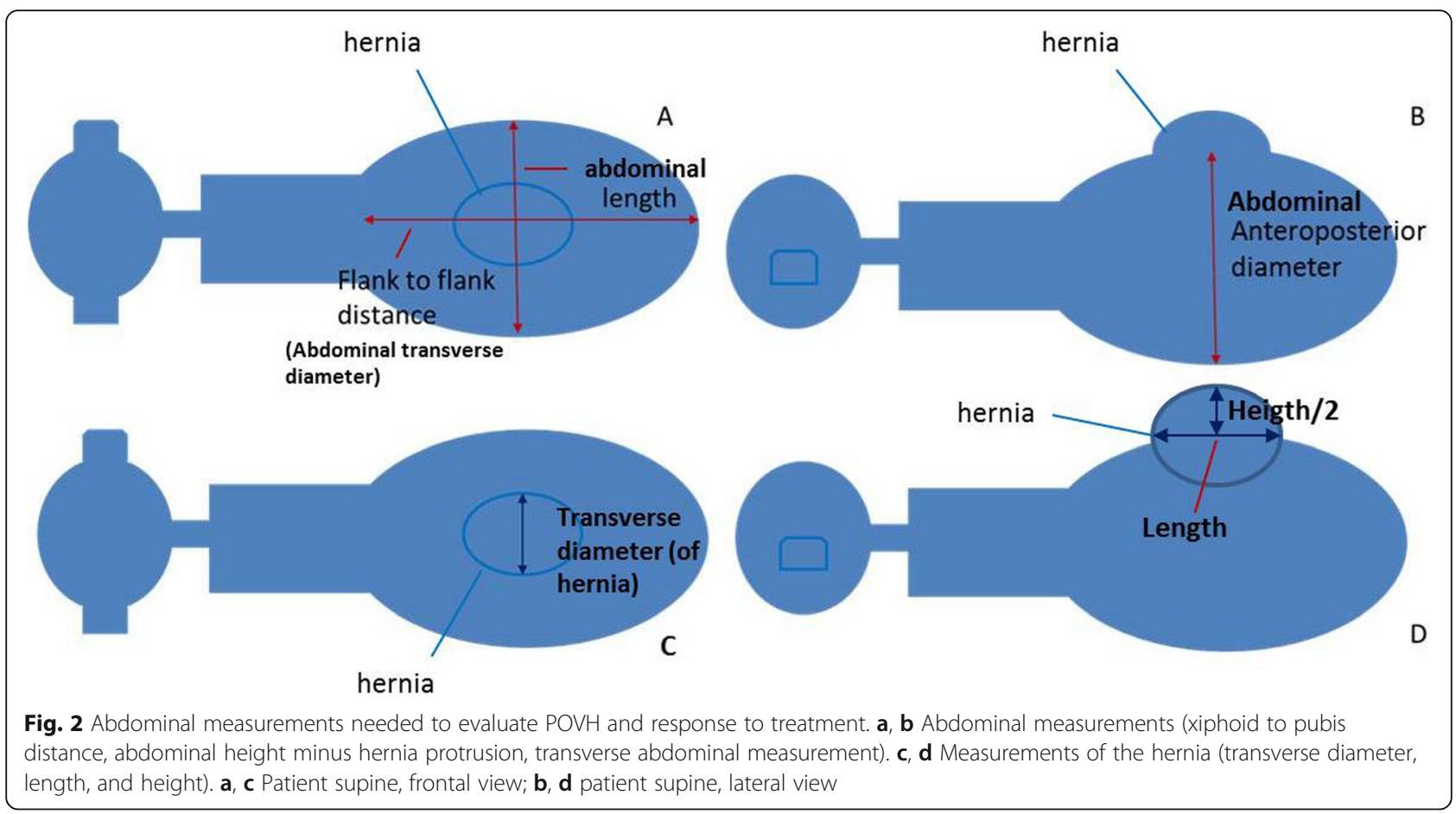

PPP Air will be instilled daily via a permanent catheter inserted in one of the lower abdominal quadrants, from 10 days before the date predicted for surgery. The volume to be injected is controlled by patients' discomfort, as daily measuring abdominal pressures would be impractical. It is difficult to address the risk of venous thrombosis in children, but phasic and repetitive caval compression is to be expected and pharmacologic prophylaxis with low-molecular-weight heparin should probably be added.

\section{Discussion}

BTI has been proved safe and useful in the treatment of $\mathrm{CIH}$ in adults. The advantages are not limited to perioperative limitation of tension and avoiding abdominal compartment syndrome, but also extended to the postoperative period, promoting better cicatrization, lower incidence of recurrences, and better pain control. All of these advantages allow us to avoid prolonged mechanical ventilation. Muscle spasm secondary to pain is minimized, allowing cicatrization under lower pressures and no lateral traction of the sutures.

The published experience of BTI to treat POVH is scarce and of a low level of evidence (case reports), but the proposal is logical and probably safe, as BTI has been used to treat many different diseases affecting children with a favorable safety profile $[28,19]$. However, in the most severe POVH cases, the superior limits of the hernia may be very near to osseous limits (ribs), associate to spherical "extra-abdominal" hernias with narrow necks and/or contain liver (solid non-compressible viscera). These characteristics may limit the success of BTI. Prospective studies are needed to verify the limitations of BIT in POVH. Especially in cases of "external" spherical hernias with a narrow neck, the situation worsens after the child assumes a predominantly orthostatic posture (after learning to walk), transforming the spherical hernia in a pending structure [25]. In such cases, auxiliary methods to maintain the position of the herniated structures (binders and compression bandages) or to augment the volume of the abdominal cavity (PPP and expanders) are probably needed. Another important point to consider is that the diaphragm is frequently flattered in POVH children, limiting the typical piston-like diaphragmatic function, which may affect respiratory mechanics in the postoperative period in a different way from that of $\mathrm{CIH}$ affecting adults.

We are aware that the equations we propose to approximate the volumes of the abdominal cavity show a degree of imprecision: the abdominal cavity is not a perfect ellipsoid. However, the measurements proposed are meant as rough approximations and are probably sufficient to judge the situation and to compare pre and post-intervention parameters and are used in a multitude of clinical situations, e.g., measurement of abdominal tumors. Moreover, this method is simple and without risks to the patients.

We were, unfortunately, unable to suggest specific air volumes to inject at each session of PPP. The hypoplastic abdominal cavity in those children does not allow the 
usage of normal volumetric formulae used for peritoneal dialysis and/or video laparoscopy. Daily measurement of abdominal pressure is impractical and invasive (needing catheterization of the bladder or stomach), and the distensibility of the abdominal + hernia cavities is difficult to calculate and may vary between cases. In children, because of a lack of cooperation, the volumes injected will probably be undervalued at the bedside. Those limitations will probably modulate the results of PPP in children, but there are no available data to evaluate this aspect. We believe that the need to associate PPP to BIT in children has to be defined in a case to case basis.

The proposal of pharmacological thromboprophylaxis is empirical, based on the theoretical risks associated with relatively bed-ridden children subjected to daily compression of inferior vena cava during PPP. We consider the risks associated with low-weight heparin in relatively low doses for a short time as acceptable in this particular situation.

\section{Conclusion}

The usage of BTI to induce preoperative muscular relaxation in preparation of $\mathrm{CIH}$ repair in adults is effective, safe, and superior to other methods of $\mathrm{CIH}$ repair. Experience with the method in children with POVH is limited to a few case reports. POVH, however similar, differs from $\mathrm{CIH}$ in some important physiological aspects, especially the presence of abdominal wall hypoplasia, osseous superior limits, and a flatter diaphragm. Multicentric prospective studies will be essential to prove the usefulness of our protocol.

\section{Abbreviations \\ POVH: Post-omphalocele ventral hernias; BTI: Botulinum toxin injectionos: $\mathrm{ClH}$ : Complex incisional hernia; PPP: Post-operative pneumoperitoneum; EMG: Electromyography; MCM: Myofascial compartment mobilization; US: Ultrasound; CT: Computerized tomography; IU: International units; OEM: External oblique muscle; OIM: Internal oblique muscle; \\ TAM: Transversus abdominis muscle}

\section{Acknowledgements}

None

\section{Authors' contributions}

LEJ: design of the paper, acquisition of data, data analysis. drafting and critical review of the manuscript. TCL: acquisition of data, data analysis. drafting and critical review of the manuscript. CF: acquisition of data, data analysis. drafting and critical review of the manuscript. SD: acquisition of data, data analysis. drafting and critical review of the manuscript. All authors that appear in the submission approved the final manuscript that was submitted and agree to be responsible and accountable for all aspects of this research

\section{Funding}

None
Ethics approval and consent to participate

Not applicable (an ethical committee approval was waived due to the type of research (review and theoretical proposal of a protocol).

\section{Consent for publication}

Not applicable

\section{Competing interests}

None

Received: 5 August 2020 Accepted: 20 October 2020

Published online: 17 December 2020

\section{References}

1. Elstner KE, Read JW, Rodriguez-Acevedo O, Cosman PH, Dardamo AN, et al. Preoperative chemical component relaxation using Botulinum toxin A: enabling laparoscopic repair of complex ventral hernia. Surg Endosc. 2017;31:761-8.

2. Weissler JM, Lanni MA, Tecce MG, Carney MJ, Shubinets V, Fischer JP. Chemical component separation: a systematic review and meta-analysis of botulinum toxin for management of ventral hernia. J Plast Surg and Hand Surg. 2017:51:366-74.

3. Cakmak M, Caglayan F, Somuncu S, Leventoglu A, Ulusoy S, Akman H, Kaya M. Effect of paralysis of the abdominal wall muscles by botulinum A toxin to intraabdominal pressure: an experimental study. J Pediatr Surg. 2006;41:821-5.

4. Rodriguez-Acevedo O, Elstner KE, Jacombs A, Read JW, Martins RT, Arduini $F$, et al. Preoperative botulinum toxin A enabling defect closure and laparoscopic repair of ventral hernia. Surg Endosc. 2018;32:831-9.

5. Rombaldi MC. S Neto WF, Holanda FC, Cavzzola LT, Fraga JC. Ventral hernia secondary to giant omphalocele in a child: combined approach of botulinum toxin and preoperative progressive pneumoperitoneum. Hernia https://doi.org/10.1007/s10029-019-02084-7.

6. Jensen KK, Hensler M, Arnesen RB, Jensen K, Jorgensen LN. Patient with a giant umbilical hernia treated preoperatively with botulinum toxin type $A$. Ugeskr Laeger 2017, 179 pii:V09160648, PMID 28115053.

7. Chavez-Tostado KV, Cardenas-Lailson LE, Perez-Trigos H. Resultado de la aplicacion preoperatoria de toxina botulínica A en el tratamento de hérnias incisionales gigantes. Rev Hispanoam Hernia. 2014;2:145-51.

8. Elstner KE, Read JW, Rodriguez-Acevedo O, Ho-Shon K, Magnussen J, Ibrahim N. Preoperative progressive pneumoperitoneum complementing chemical component relaxation in complex ventral hernia repair. Surg Endosc. 2017:1914-22.

9. Farooque F, Jacombs AS, Roussos E, Read JW, Dardano AN, Edye M et al. Preoperative abdominal muscle elongation with botulinum toxin $\mathrm{A}$ for complex incisional hernia repair. ANZ J Surg. 2016;86:79-83.

10. Bueno-Lledo J, Torregrosa A, Ballester N, Carreno O, Carbonell F, et al. Preoperative pneumoperitoneum and botulinum toxin type $A$ in patients with large incisional hérnia. Hernia. 2017:21:233-43.

11. Bueno-Lledo J, Torregrosa A, Jimenez R, Pastor PG. Preoperative combination of progressive pneumoperitoneum and botulinum toxin type A in patients with loss of domain hernia. Surg Endosc. 2018;32:3599-608.

12. Nielsen $M O$, Bjerg J, Dorfelt A, Jorgensen LN, Jensen KK. Short-term safety of preoperative administration of botulinum toxin A for the treatment of large ventral hernia with loss of domain. Hernia. https://doi.org/10.1007/s10029019-01957-1.

13. Ibarra-Hurtado TR, Nuno-Guzman CM, Miranda-Diaz AG, Troyo-Sanroma R, Navarro-lbarra R, Bravo-Cuellar L. Effects of botulinum toxin type A in lateral abdominal wall muscles thickness and length of patients with midline incisional hernia secondary to open abdomen management. Hernia. 2014; 18:647-52.

14. Zielinski MD, Goussous N, Schiller HJ, Jenkins D. Chemical components separation with botulinum toxin $\mathrm{A}$ : a novel technique to improve fascial closure of the open abdomen. Hernia. 2013;17:101-7.

15. Zendejas B, Khasawneh MA, Srvantstyan B, Jenkins DH, Schiller HJ, Zielinski MD. Outcomes of chemical component paralysis using botulinum toxin for incisional hernia repairs. World J Surg. 2013;37:2830-7.

16. Elstner KE, Read JW, Saunders J, Cosman PH, Rodriguex-Acevedo O, et al. Selective muscle botulinum toxin A component paralysis in complex ventral hernia repair. Hernia. https://doi.org/10.1007/s10029-019-01939-3. 
17. Ibarra-Hurtado TR, Nuno-Guzman CM, Echeagaray-Herrera JE, Robles-Velez E, Gonzalez-Jaime JJ. Use of botulinum toxin type A before abdominal wall hernia reconstruction. World J Surg. 2009;33:2553-6.

18. Bueno-Lledo J, Gallud AT, Rosellon RJ, Tatay FC, Pastor PG, Diana SB, Hernandez Jl. Preparacion preoperatoria de la hernia con perdida de domicilio. Neumoperitoneo progresivo y toxina botulinica do tipo A. Cir Esp. 2017:245-53.

19. Farooque

20. Smoot $D$, Zielinski $M$, Jenkins $D$, Schiller $H$. Botox $A$ injectionfor pain after laparoscopic ventral hernia. A case report. Pain Medicine. 2011;12:1121-3.

21. Tanaka EY, Yoo JH, Ultiyama EM, Birolini D, Rasslan S. Computerized tomography scan method for calculating the hernia sac and abdominal cavity volume in complex large incisional hernia with loss of domain. A prospective study. Hernia. 2010;14:63-9.

22. van Eijck FC, de Blaauw I, Bleichrodt RP, Rieu PN, van der Staak FH, Wijnen $\mathrm{MH}$, Wijnen RM. Closure of giant omphaloceles by the abdominal wall componente separation technique in infants. J Pediatr Surg. 2008:43:246-50.

23. Miller EA, Goldin A, Tse GN, Tse R. Extended component separation for repair of high ventral hernia in pediatric omphalocele. Plast Reconstr Surg Glob Open. 2015 Sep 4;3(9):e503.

24. Belloli G, Battaglino F, Musi L. Management of giant omphalocele by progressive external compression: case report. J Pediatr Surg. 1996:31:1719-20.

25. Sander S, Elicevik M, Unal M. Elastic bandaging facilitates primary closure of large ventral hernias due to giant omphaloceles. Pediatr Surg Int. 2001;17: 664-7.

26. Kruit AS, Al-Ani SA, Jester I, Jester A. Multilayered flap technique: a method for delayed closure of giant omphalocele. Ann Plast Surg. 2016;76:680-3.

27. Food and Drug Administration: botulinum toxin instructions https://www. accessdata.fda.gov/drugsatfda_docs/label/2019/103000s5309/bl.pdf.

28. Kinnett D. Botulinum toxin $\mathrm{A}$ injections in children: technique and dosing issues. Am J Phys Rehab. 2004;83:S59-64.

29. Hassouna T, Gleason JM, Lorenzo AJ. Botulinum toxin A's expanding role in the management of pediatric lower urinary tract dysfunction. Curr Urol Rep. 2014;15:426. https://doi.org/10.1007/s11934-014-0426-1.

30. Lee SL, Beyer TD, Kim SS, Waldhausen JHT, Healey PJ, Sawin RS, Ledbetter DJ. Initial nonoperative management and delayed closure for treatment of giant imphaloceles. J Pediatr Surg. 2006;41:1845-9.

\section{Publisher's Note}

Springer Nature remains neutral with regard to jurisdictional claims in published maps and institutional affiliations.

\section{Submit your manuscript to a SpringerOpen ${ }^{\circ}$ journal and benefit from:}

- Convenient online submission

- Rigorous peer review

- Open access: articles freely available online

- High visibility within the field

- Retaining the copyright to your article

Submit your next manuscript at $\boldsymbol{\nabla}$ springeropen.com 